\title{
Application of Quality Control Methods in Lowering Rejection Rate of Casting Products
}

\author{
Zechao Du a , Youkun Su \\ Tianjin University of Technology, Tianjin, China \\ a869821470@qq.com
}

Keywords: Control; Pareto Diagram; Cause and Effect Diagram; PDCA Cycle.

\begin{abstract}
Through analysis on some enterprise's main product, I find that there are most wasters in furnace tag. For the sake of ameliorating status quality, I use one method namely Pareto Diagram of quality tools to analyze and deal with data. Then the main quality vice can be identified well, we should set down the target value. To locate the critical factor of problem, Cause and Effect Diagram is applied to analyze man, machine, material, method, and environment and so on. Then, in the light the causes, formulate reasonable countermeasures and bring it into effect. After putting them into practice, pay close attention to the situation of the performance from time to time. The whole process is based on PDCA circles so as to make sure the process carried on successfully and put an end to these vices radically.
\end{abstract}

\section{Introduction}

Casting technology develops rapidly in advanced industrial countries nowadays. Their objectives are: (1) to protect the environment, reduce and eventually eliminate the pollution; (2) to improve the quality and reliability of castings, produce high quality defect-free castings; (3) to reduce production costs; (4) to shorten delivery time. Compared with developed countries, China is weak in aspects of quality, efficiency, consumption, labor conditions and environmental ${ }^{[1]}$. In order to eliminate these gaps, meet the needs of China's economic construction, and development the casting industry, casting industry in China should improve casting quality and economic efficiency, Management need to be strengthened to confront both the domestic and international markets ${ }^{[2]}$. It's necessary to improve the quality of the industrial structure with the rational allocation of resources, promote moderate economies of scale and continue to apply advanced production technology and technical equipment renovation foundry industry to achieve cleaner production.

\section{From problem-faced to problem-solved}

In this paper, we analyzed hob, the main product of DISA Company with higher rejection rate. And then analyze product quality defects with frequency occurrence of the waste. Identify the, major quality defects in quality management tools and in the method of data analyzing and processing, then develop target. Use Pareto chart and causal analysis from the human figure, the elements of machine, material, method, and other aspects, to identify the few factors that are causing the most of problem. Formulate realistic countermeasures, and develop strategies for implementation. Keep an eye in the implementation process to ensure the smooth implementation of the scheme, and then analyzed using the method of processing data corresponding measures taken after comparison with the previous chart, check and record the implementation effect. If the desired goal not achieved, another cause analysis be done. Develop work instructions and take appropriate measures to consolidate. Evaluate and summarize the effect to make the final for this improvement process for future reference. Accomplish the whole process according to PDCA cycle implementation, fundamentally prevent such defects from happening again. 


\section{Plan-Do-Check-Act}

PDCA cycle is divided into the following four stages:

Plan: To improve your operations first by finding out what things are going wrong (that is to identify the problems faced), and come up with ideas to solve these problems.

Do: Changes occur to solve the problems on a small scale first. This minimizes disruption to routine activity while testing whether the changes will work or not.

Check: Identify whether the small scale or experimental changes are achieving the desired result or not. Also, continuously check nominated key activities (regardless of any experimentation going on) to ensure that you know what the quality of the output is at all times to identify any new problems when they crop up.

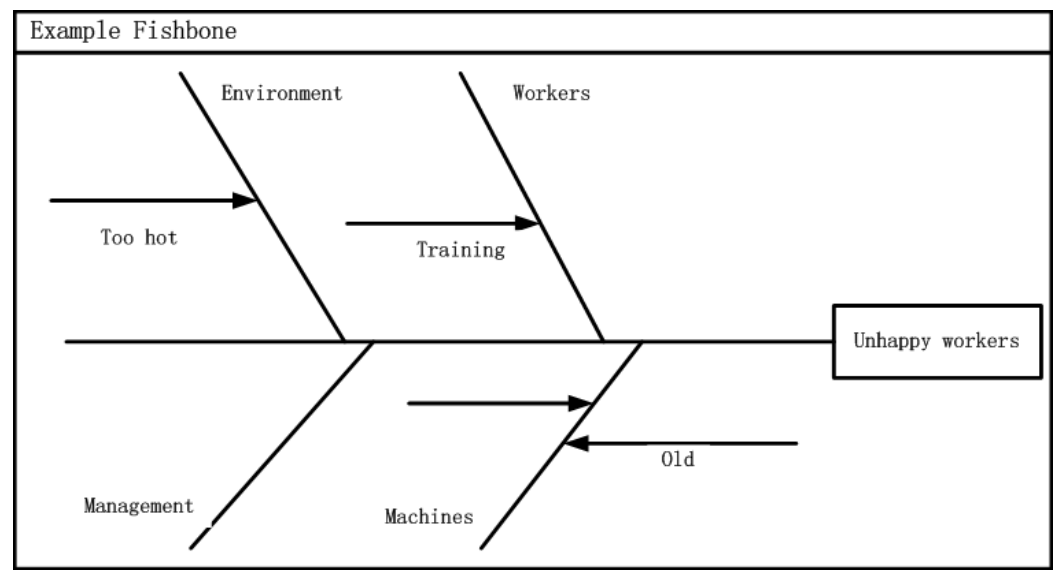

Act: To implement changes on a larger scale if the experiment is successful. This means making the changes a routine part of your activity. Also Act to involve other persons (other departments, suppliers, or customers) affected by the changes and whose cooperation you need to implement them on a larger scale, or those who may simply benefit from what you have learned (you may, of course, already have involved these people in the Do stage).

Use the PDCA Cycle to coordinate your continuous improvement efforts. It both demonstrates and emphasizes that improvement programs must start with careful planning, must result in effective action, and must move again to careful planning in a continuous cycle. Also use the PDCA Cycle diagram in team meetings to take stock of what stage improvement initiatives are at, and to choose the appropriate tools to see each stage through to successful completion.

\section{Cause \& Effect Diagram}

In quality analysis, if you want to find out the primary and secondary relationship between the relevant factors of the same layer in the visual methods, Pareto diagram can do the job ${ }^{[4]}$. However, the longitudinal causal relationship exist, this requires a method that can deal with both of the relationship. Cause \& Effect Diagram can solve this problem. It is a tool to sort out and analyze various factors that affect quality.

Consider this figure, Cause \& Effect Diagram can represent the thinking process to explore the problem. It helps analyze problems step by step following up a clue and seizing the culprit. Find the main reason for quality at first, then find out smaller reasons and some other reasons. Identify the direct cause eventually. This methodical analysis layer by layer, can clearly show the "cause--effect ", "means --target" relationship, so that the problems fully displayed. Cause \& Effect Diagram are composed of characteristics, causes, limbs. 


\section{Present Situation of Quality}

DISA factory mainly produces grate roasting net and tableware. In tougher checks, it occurs that the number of hob scrap and defective products have greatly increased than before, abnormal cases increased. Hobs products are in different sizes and all kinds of shapes, so the quality is not stable. What's more, the rejection rate of the grate is not stable annually. The scrap rate changes between $11.26 \%-30.62 \%$. The average rejection rate is in $20.46 \%$. Such numbers should be higher for the foundry enterprises, which will greatly affect the company's benefit.

The analysis shows that the factors causing the waste is voids, blowhole, sand, partialbox, fracture and fire flow. Making the arrangement graph to find the main reasons lead to waste, drawing as follows.

The following are main factors analyzed and identified to produce voids:

1) quality-check personnel slack off;

2) Sand for runner box is not suitable [5-7];

3) Pouring system is not reasonable;

4) Workshop environment is bad, the external sand gets into the cavity.

Solutions

Work on solutions according to main factors.

1) Invite specialist for expert guide so that quality-check personnel can accurately understand the inspection standard

2) Use special sand for runner box

3) Find appropriate gating system

4) Workshop environment is bad, the external sand gets into the cavity.

Effect Inspection

After improvement activities of two months, to improve the quality of the products after the confirmation, the results are as follows:

Table 1 FOCTORS

\begin{tabular}{|c|c|c|c|c|}
\hline Unqualified type & Unqualified & SUM & Ratio(\%) & SUM (\%) \\
\hline voids & 30 & 30 & 75 & 75 \\
\hline blowhole & 5 & 35 & 12.5 & 87.5 \\
\hline sand & 3 & 38 & 7.5 & 95 \\
\hline else & 2 & 40 & 5 & 100 \\
\hline SUM & 40 & & 100 & \\
\hline
\end{tabular}

Table 2 FOCTORS

\begin{tabular}{|c|c|c|c|c|}
\hline Unqualified type & Unqualified & SUM & Ratio(\%) & SUM (\%) \\
\hline voids & 16 & 16 & 40 & 40 \\
\hline blowhole & 10 & 26 & 25 & 65 \\
\hline sand & 8 & 34 & 20 & 85 \\
\hline else & 6 & 40 & 15 & 100 \\
\hline SUM & 40 & & 100 & \\
\hline
\end{tabular}

\section{Summary}

In this paper, a more comprehensive improvement scheme for the casting product quality is put forward on the basis of theoretical analysis by using the methods of quality control. In the research some work has been done in the following:

Review status of quality of casting products home and abroad, introduces the background and explain the contents and the methods of this study ${ }^{[8]}$. 
Some quality management tools are introduced, namely, Pareto Diagram, PDCA cycle and Cause \& Effect Diagram.

Analyze the status of quality of company and identify what to achieve. Analyze using the quality control method above, find out the main factors to improve.

Find out the main factors, then formulate strategies and put them into practice. The results of the implementation should be dealt with through inspection and evaluation. The activities end with formulation of consolidation measures and standardization. ${ }^{\text {[9] }}$

Although this paper has achieved the desired goal, blowhole is still the main factor affecting the casting. The next step should be in accordance with the above methods when striving to find a better solution.

\section{References}

[1] Zhang Liguang, Foundry equipment and technology of China, 2000 (4):13 16

[2] Chen Zongmin. Total quality control (TQC) in casting quality control, Foundry equipment research, 2000:51 54.

[3] Dale, B.G.,Lascelles, D.M,Total quality management adoption Revisiting the levels, TQM Magazine, 2000-3:18 28.

[4] Cai Yida, Analysis of application of Pareto diagram, Quality in Shanghai, 2004(7):18 24.

[5] Witteveld, Andreas D,Effective sand-control completions in a remote development Chad,IADC/SPE Drilling Conference, 2004.8:65 77.

[6] Bi Weisheng, Several factors affecting the quality of castings in low pressure casting, Foundry equipment and technology of China, 2004(5):35 38.

[7] hang Zhi,. Influence of molding sand on casting quality and Solutions, Tendency of science and Technology, 2003(1):64 70.

[8] Zeng Qingsheng, Process specification and quality control of aluminium alloy casting, Mechanical Engineering College of University of South China, 2002. 4:48 52.

[9] Zhuang Minghui, Improvement of casting quality Field Management, 2002(7):23 24. 